\title{
Attitudes of mental health practitioners to the Hippocratic Oath: tradition and modernity in psychiatry
}

\author{
AIMS AND METHOD \\ To establish whether psychiatrists \\ believe that medicine should be \\ practised according to the principles \\ of the Hippocratic Oath, an anon- \\ ymised postal questionnaire survey \\ was conducted of all medical staff at \\ the Caludon Centre, an 80-bed in-
}

\author{
patient mental health unit in \\ Coventry. \\ RESULTS \\ Thirty-three respondents ( $82.5 \%$ ) \\ believed that medicine should be \\ practised according to the Oath. \\ Support for the 15 separate
}

\author{
statements derived from the Oath \\ varied considerably. \\ CLINICAL IMPLICATIONS \\ The principles of the Oath remain an \\ important guide to the ethical basis \\ of medical practice for most medical \\ staff surveyed.
}

Written in the 5th century $\mathrm{BC}$, the Hippocratic Oath has been described as the first serious attempt to bring together philosophy, ethics and therapy in an integrated system of medical practice (Zilboorg \& Henry, 1941). Hippocratic ethics influence many contemporary medical oaths and ethicists (Roddy \& Jones, 2002), but although it is seen as an inspirational statement of the ethos of medicine by some, the relevance of the Hippocratic Oath to modern clinical practice continues to be questioned (Loefler, 2002). Very little is known, however, about psychiatrists' attitudes to the Hippocratic Oath and whether they consider it still possible to practise medicine according to the Oath. The aim of this study was to ask how far psychiatrists believed that their practice reflected the principles of the Hippocratic Oath.

\section{Method}

A survey was conducted in February 2004 of psychiatrists working at the Caludon Centre, an 80-bed mental health in-patient unit in Coventry. An anonymised questionnaire was constructed consisting of 15 statements or closed questions restating the original Oath (British

Medical Association, 2004) using a simple Likert scale to measure agreement with each statement (available from the authors on request). We added one 'summary' question which asked whether it was still possible to practise medicine according to the Oath. Every doctor in the unit was personally approached by the authors and asked to participate. Results were collated and analysed with the Statistical Package for the Social Sciences version 12 for Windows.

\section{Results}

Of the 44 psychiatrists at the Caludon Centre, 40 (91\%) completed the questionnaire; 17 were consultants and 23 were junior doctors. Their age ranged from 27 to 74 years (mean 34 years); 32 (80\%) were male and 8 (20\%) female.
The main results of the survey are summarised in Tables 1 and 2 . There was no statistically significant difference between the response of consultants and junior doctors for any of the statements. A substantial majority of respondents believed that medicine should be practised according to the Hippocratic Oath; unconditional agreement with individual statements varied from 22 to $100 \%$.

The first four statements specify the duties of a medical trainee towards his teachers and other doctors. An overwhelming majority (97\%) of medical staff at the Caludon Centre said they respected their teachers. Most were still willing to provide help in both professional $(86 \%)$ and other matters (64\%). The tradition of solidarity among doctors also appears to remain strong, with $81 \%$ of respondents claiming always or frequently to treat other doctors as brothers. There was greater ambiguity about the transmission of medical knowledge: $58 \%$ of doctors supported the dissemination of medical knowledge to those who do not follow medical ethics and obey medical law.

The next part of the Oath summarises the values and principles underpinning medical practice: treatment according to the patient's best interests (beneficence), avoiding harm (non-malfeasance), prohibition of abortion and assisted death and practising within one's competence and with a high degree of personal integrity. The results show strong support for the principles of beneficence and non-malfeasance: $83 \%$ of respondents claimed to always have their patients' health as their first consideration, $17 \%$ only frequently; $92 \%$ declared that they always avoid harming their patients, with $8 \%$ acknowledging that it has not always been possible; $77 \%$ were against the use of medical knowledge to end a patient's life in any circumstances; $18 \%$ were prepared to consider some exceptions and $6 \%$ were rarely or never against euthanasia. The statement prohibiting the use of abortion produced the most ambiguous response: $25 \%$ of doctors were always against and $25 \%$ were never against termination of pregnancy by their patients. The rest remained ambivalent $-33 \%$ of psychiatrists reject abortion frequently, a further $17 \%$ rarely. The question on

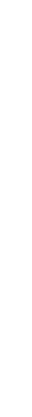


Table 1. Agreement with statements concerning the Hippocratic Oath for 40 psychiatrists ${ }^{1}$

original papers

\begin{tabular}{|c|c|c|c|c|}
\hline \multirow[b]{2}{*}{ Statement } & \multicolumn{4}{|c|}{ Agreement } \\
\hline & $\begin{array}{c}\text { Always } \\
n(\%)\end{array}$ & $\begin{array}{c}\text { Frequently } \\
n(\%)\end{array}$ & $\begin{array}{l}\text { Rarely } \\
n(\%)\end{array}$ & $\begin{array}{l}\text { Never } \\
n(\%)\end{array}$ \\
\hline I show my teachers unconditional respect & $21(54)$ & $17(43)$ & $1(3)$ & $0(0)$ \\
\hline I help my teachers in professional matters, if required & $17(46)$ & $15(41)$ & $5(13)$ & $0(0)$ \\
\hline I have my patient's health as my first consideration & $33(83)$ & $7(17)$ & $0 \quad(0)$ & $0(0)$ \\
\hline I avoid harming my patients & $37(92)$ & $3(8)$ & $0(0)$ & $0 \quad(0)$ \\
\hline I am against the use of medical knowledge to end the life of my patients & $30(77)$ & $7(18)$ & $1(3)$ & 1 (3) \\
\hline I am against the termination of pregnancy in my patients & $9(25)$ & $12(33)$ & $6(17)$ & $9(25)$ \\
\hline I practise my profession with conscience and dignity & $33(83)$ & $7(17)$ & $0 \quad(0)$ & $0 \quad(0)$ \\
\hline I hold the information about my patients in confidentiality & $30(75)$ & $10(25)$ & $0 \quad(0)$ & $0 \quad(0)$ \\
\hline
\end{tabular}

1. Responses were missing for some statements.

Table 2. Responses to closed questions of 40 psychiatrists

\begin{tabular}{|llc} 
& \multicolumn{2}{c}{ Response } \\
\cline { 2 - 3 } Closed question & $\begin{array}{c}\text { Yes } \\
n(\%)\end{array}$ & $\begin{array}{c}\text { No } \\
n(\%)\end{array}$ \\
\hline $\begin{array}{l}\text { I impart my medical knowledge only to } \\
\text { those who follow medical ethics and } \\
\text { obey medical law }\end{array}$ & $15(42)$ & $21(58)$ \\
$\begin{array}{l}\text { I believe that medicine should be practised } \\
\text { according to the Hippocratic Oath }\end{array}$ & $33(83)$ & $7(17)$ \\
\hline $\begin{array}{l}\text { 1. Responses were missing for this question. } \\
\end{array}$ & \\
\hline
\end{tabular}

termination of pregnancy also had the highest noncompletion rate, with some $10 \%$ of respondents choosing not to answer the question.

The last part of the Oath deals with maintaining the integrity of the therapeutic relationship. All of the respondents in our survey agreed with this principle: $83 \%$ declared that they always practised their profession with conscience and dignity; the other $17 \%$ did so frequently; $98 \%$ of psychiatrists condemned corruption and $100 \%$ were against sexual relationships with patients; $77 \%$ stated that they undertake interventions only within their competence, with $23 \%$ of respondents admitting that they had dealt with situations beyond their clinical expertise. Maintaining confidentiality in psychiatry is sometimes problematic. A quarter of psychiatrists acknowledged that it was not always possible to hold information about their patients in complete confidentiality.

\section{Discussion}

Only one respondent $(2.5 \%)$ indicated that they supported all the statements derived from the Oath and the level of support for the other statements varied.
Statements prohibiting the abuse of the therapeutic relationship and those supporting the Hippocratic principles of beneficence and non-malfeasance attracted almost unanimous support. However, errant behaviour may not have been declared for fear of professional censure. Moreover, respondents were presented with a restatement of the Oath rather than the original. One principle, the prohibition of sharing medical knowledge with others, was rejected by a small majority (58\%) of respondents. The most equivocal responses concerned statements about treating doctors as brothers (only $26 \%$ always agreed), forbidding abortion ( $25 \%$ never agreed with this) and helping teachers in non-professional matters (22\% always agreed). Despite these ambiguities, our survey suggests that the majority of psychiatrists believe that medicine should be practised according to the principles of the Hippocratic Oath. However, because of the small sample size the results may not reflect the view of all UK psychiatrists.

In the past 25 years most of the major innovations in medical ethics have come from outside the Hippocratic tradition, notably from law, politics and economics. The role of traditional medical ethics in contemporary medicine is unclear, although personal integrity, trust and acknowledging tradition have been identified as key components of postmodern psychiatric ethics (Dyer, 1999). Bioethics has been criticised for failing to recognise how far medicine is a value-based as well as an evidence-based discipline (Fulford, 1993). We believe the level of support shown in our survey for the principles of the Oath supports the notion that moral values are still felt to be important to contemporary psychiatric practice. According to Jaspers, tradition is the memory of the profession (Jaspers, 1963) and this needs to be safeguarded in the light of the multiple and changing demands of society on medicine. These demands can be creative, helping to redefine the role of the profession in a postmodern world. Such a redefinition, however, should also be informed by traditional values and beliefs. 
These values can make us aware of our history and identity and provide guidance in a time of change. Articulated in a contemporary form, Hippocratic values such as avoiding harm, acting in the best interest of the patient, compassion, integrity, honesty and respect for human life maintain their relevance and prove that goodness in medical practice does remain continuous across the ages.

\section{Declaration of interest}

None.

\section{References}

BRITISH MEDICAL ASSOCIATION (2004) Handbook of Ethics and Law. London: Medical EthicsToday. The BMA's
DYER, A. R. (1999) Psychiatry as a profession. In Psychiatric Ethics (eds S. Bloch, P. Chodoff \& S. Green) pp. 74-77. Oxford: Oxford University Press.

FULFORD, K. R. (1993) Bioethical blind spots: four flaws in the field of view of traditional bioethics. Health Care Analysis, 1, 155-162.

JASPERS, K. (1963) General Psychopathology (3rd edn) pp. 814-815. Manchester: Manchester University Press.

OEFLER, I. (2002) Why the Hippocratic ideals are dead. BMJ, 324, 1463 .

RODDY, E. \& JONES, E. (2002) Hippocratic ideals are alive and well in the 21st century. BMJ, 325, 496.

ZILBOORG, G. \& HENRY, G. (1941) A History of Medical Psychology. London: Allen \& Unwin.

*Marek Marzanski Consultant Psychiatrist, CoventryTeaching Primary Care Trust, The Caludon Centre, Clifford Bridge Road, Coventry CV2 2TE, email: marek.marzanski@coventrypct.nhs.uk, Tim Coupe Clinical Audit/Effectiveness Officer, Padmapriya Musunuri Senior House Officer, CoventryTeaching Primary CareTrust, The Caludon Centre, Coventry

\section{JULES MASON, TINA IRANI, GARYFALLIA FOUNTOULAKI, SYLVIA WARWICK,} JANE DA ROZA DAVIS AND PETER SUDBURY

\section{Psychiatry at night: experience of the senior house officer}

\begin{abstract}
AIMS AND METHOD
We gathered detailed prospective data for first on-call activity of senior house officers (SHOs) in order to help plan changes in service provision so that SHOs in psychiatry complied with the Working Time Directive and to determine whether service changes affected training experience while on call. The incumbent $\mathrm{SHO}$ s designed a simple form to monitor on-call activity in West Berkshire.
\end{abstract}

\author{
RESULTS \\ Admissions and assessments make up \\ a quarter of calls but three-quarters \\ of the work. An overnight crisis \\ service reduced the number of \\ assessments made by SHOs out of \\ hours by $68 \%$. Screening of calls by a \\ senior nurse reduced the number of \\ calls about in-patients by $60 \%$ on \\ weekday nights. Between $73 \%$ and \\ $100 \%$ of calls about in-patients after \\ midnight were for assessment of \\ patients in seclusion and rapid \\ tranquillisation.
}

\section{CLINICAL IMPLICATIONS}

This survey helped to plan service delivery and to monitor the training of SHOs during on call. Screening of calls by a senior nurse, alternatives to seclusion and nurse-led prescribing for rapid tranquillisation would have the largest impact on the work generated by in-patients. The overnight crisis service reduced the number of assessments, but might have an adverse impact on training.
Monitoring of hours spent on call by senior house officers (SHOs) is compulsory to comply with the Working Time Directive (WTD Expert Group, 2004), but this does not yield detailed information of what junior doctors are called to do during on-call hours (Department of Health, 2005). The workload of trainees on call has been studied in acute trusts (Baldwin et al, 1997; Paice et al, 1997; Hurley \& Patterson-Brown, 1999; Brown et al, 2002; Department of Health, 2005), but the nature of the work is very different in medicine, paediatrics and surgery compared with psychiatry (Callaghan et al, 2005). The major differences are the greater time necessary for assessment and admission, and the less frequent use of emergency investigations.

Callaghan et al (2005) showed that SHOs in psychiatry appreciated their time on call as a learning experience, with nearly two-thirds having confidence in their decision-making. In that study SHOs made retrospective estimates of the on-call work that was directly related to training: admissions, assessments, risk assessments, level of senior support, developing management plans and team-working. Herzberg \& Paice (2002) described a perceived improvement in psychiatry training after interviewing SHOs from London training schemes. In Learning Objectives for SHOs (Royal College of Psychiatrists, 2002) there is no reference to the learning objectives for the on-call period apart from the general expectation that by the end of basic training psychiatrists should be able to assess patients in a variety of settings. The Basic Specialist Training Handbook (Royal College of Psychiatrists, 2003) states that each trainee should do 55 nights on call during their basic training, but not what should be achieved during these nights on call.

We gathered detailed prospective data about first on-call activity to help to resolve such issues as resident $v$. non-resident SHOs, tasks that could wait or be taken over by other professionals (Modernising Agency, 2006), the impact of an overnight crisis service, the screening of 